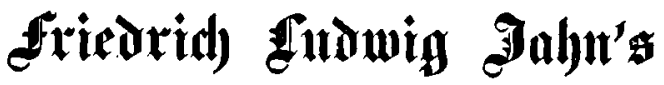

\section{Deutidge $\mathfrak{I} \mathfrak{u} \mathfrak{n} \mathfrak{f} \mathfrak{n} \mathfrak{f t}$.}

$3 \mathfrak{u n}$ zweiten $\mathfrak{M a l e}$

un

febr vermebrt beraubgegeben.

Mit 7 Rupfertafeln.

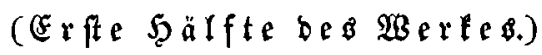

\section{$\boldsymbol{3} \in \mathfrak{x} \mathfrak{i} u$.}

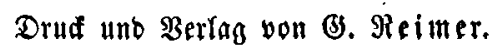

1847. 


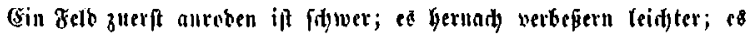

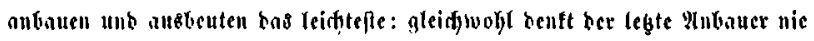

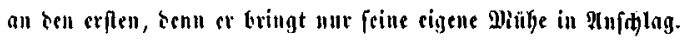

S. 5 . \&ing.

(Borrebe zur fintoebifinen Symnnfif.) 